along the part of the gill to which the crab has approximated its abdomen and within easy reach of its claws. When feeding the crab moves, or rather scrapes, its claws over the gill, and by means of the hairy nature of its claws easily catches hold of the mucus-strings entangling the food and transfers them to the region of its mouth. The claw is now scraped over the region of the mouth, and the specially hairy mouth-parts of the crab, working in an opposite direction, comb off the strings of food and press them into the mouth. The claw of this crab is apparently specially modified to enable it to be flexed about the middle of its length for giving the unusual scope of action required for the scraping movements.

It is thus seen that the pea-crab is a parasite, and no advantage of its presence to the host has yet been detected, unless it be the occasional association of the palps with the crab, for in this case the crab would be relieving the host of the necessity for transporting and expelling undesirable food; on the other hand, the crab would appear to do no more harm to the mussel than to make it collect food faster or for a longer time than would be necessary in an abundant supply of food if the crab were not there.

There is thus good reason to believe that those allies of the pea-crab which are known to live in plankton-feeding animals-for example, other bivalves and Ascidians-will be found to feed in the same way as this crab.

In the search for these pea-crabs during the summer it was observed that berried females were frequently found alone in a mussel, and that males appeared to be scarce; the method of fertilisation, therefore, was not understood, and appeared to be worth investigating. It is well known that in this crab there is a marked sexual dimorphism, the males being small, very hairy, and, it may be added, very active. while the females are large, relatively smooth, and extremely passive. Moreover, tiny females have apparently never been described. There was thus the additional problem of interest of the whereabouts of the tiny females-if, indeed, tiny females should exist. 'The whole of the phenomena suggested protandry-a suggestion that was strengthened by my obtaining a tiny female form moulted from a minute supposed male crab with a carapace only $2.7 \mathrm{~mm}$. wide. This tiny female form-now $3.3 \mathrm{~mm}$. in diameter-however, was found to have enormous spermothecæ crammed full of mature spiked sperm and only a trace of gonad, which was, however, obviously female. The moult of this specimen was now carefully examined, and found to possess the full number of abdominal appendages characteristic of the female, although otherwise not recognisable externally from a male.

Many other male-like tiny female specimens have been obtained, and also a series of moults which leave no doubt that the young male-like female attains the adult characters through a succession of moults. It is an interesting fact that all the larger females examined have been found to have their spermothecæ always full of mature sperm. It would therefore appear that this pea-crab copulates precociously at an extremely early age before settling down to its later sedentary life, and, so far as my observations have gone, it would seem that no further meeting with a male is necessary, although males have been found in the autumn inside the same host as large females; a newly moulted female, however, appears to have no charm for a male. Sexual dimorphism in the species is thus seen to be accompanied by dimorphism of the females, and the change from the male-like form of the female to the adolescent young-bearing female form appears undoubtedly to depend upon, and to occur after, copulation. It would also appear that No. 2669 , VOL. IO6] copulation normally takes place inside the host, and that the males visit mussels in their search for females, since unwary male crabs have been found with their legs or bodies trapped by the mussel closing its shell before the crab could get inside. These crabs survive the rough treatment by reason of their extraordinarily strong carapace, and creep inside the mussel later when it must perforce relax and open its shell in order to breathe. The male-like female has a similarly hard carapace which prevents the animal being crushed to death if unluckily trapped by the mussel destined to become a host. Individual crabs have been found to be lacking a leg which might very well have been lost in this dangerous operation.

The life-story of this animal is probably not yet complete, since the tiny male-like female appears to possess a different sexual apparatus from the older forms, and a single male form has been found with a carapace closely resembling that of a female. It is hoped, therefore, to complete the investigations in the near future.

The Laboratorv, Citadel Hill, Plymouth, November 10.

\section{The Energy of Cyclones.}

My objection to Mr. Deeley's suggestion (Nature, December 16, p. 502) that cyclones are caused by an access of warmth in the stratosphere is that in that case the troposphere ought to bulge upwards over the cyclone, whereas, in fact, it bulges downwards. The inversion at the boundary renders it certain that the interchange of air between the troposphere and the stratosphere is very slow, and for the few days of the life of a cyclone we may, to get a clear idea, imagine a light but impermeable film to exist at the boundary. If a patch of air above the film were warmed by any means it would expand outwards and reduce the weight on the film, which should, in consequence, rise. If, on the other hand, the film were drawn downwards, the temperature of the air above it would rise, because each air-particle as it lost in height would come under an increased pressure, and be warmed adiabatically. If, then, the air is drawn outwards horizontally from a cyclone in the upper part of the troposphere, the conditions as to temperature and the position of the top of the troposphere that are known to prevail are readily explained.

The point mentioned by Sir Oliver Lodge in his letter in Nature of November 25 has been, I think, put forward by von Besold and others, but Sir Oliver seems to have overlooked the result of the heat set free by the condensation of the vapour. Could a cubic metre of aamp air be confined in an adiabatic but extensible balloon and the vapour be condensed by any means, the result would be an increase of volume, for the expansiont due to the heat produced by the condensation would far more than balance the contraction due to loss of pressure. If, indeed, the heatenergy due to the latent heat of vapour all took the form of kinetic energy in the atmosphere, quite a trifing rainfall would suffice to produce over the same area the most violent cyclone ever recorded.

Benson, Wallingford, Berks.

W. H. Dines.

\section{The Mechanics of Solidity.}

IN Nature of November is last Mr. J. Innes pointed out that if a number of substances be arranged in order of increasing coefficient of linear expansion, then they are very nearly in a series of decreasing hardness, as shown by Brinell's, Moh's, or Auerbach's test, and he has, therefore, suggested, that it should be possible to obtain a fair 